\title{
Adsorption-Coagulation Mechanism of Composites in Treating Acid Mine Drainage
}

\author{
Liping Xiao*, Zhe Liu, Xuefei Luan and Jichi Bai \\ Department of Municipal Engineering, Liaoning Technical University, Fuxin, Liaoning, China
}

\begin{abstract}
In order to study the removal efficiency of $\mathrm{Cu}^{2+}$ from acid mine drainage by prepared bentonite-steel slag composite particles, adsorption experiment was carried out. The composite particles were characterized by X-ray Diffraction analysis technique (XRD), Scanning Electron Microscopy (SEM) and Fourier Transform Infrared spectrometer (FTIR). The results show that: the composite particles can release alkali to neutralize the acid of acid mine drainage; the adsorption and chemical precipitation of $\mathrm{Cu}^{2+}$ occurred in the whole reaction process; the removal amount of composite particles on $\mathrm{Cu}^{2+}$ was $9.88 \mathrm{mg} / \mathrm{g}$ when the reaction reached equilibrium; the FTIR spectra revealed the existence of surface complexation; the SEM micrographs suggested that the composite particles would continue to adsorb and coagulate $\mathrm{Cu}^{2+}$ after the composite particles surface adsorbing $\mathrm{Cu}^{2+}$ and forming precipitate, namely, there was synergistic reaction of adsorption and coagulation; the XRD patterns further showed the existence of cation exchange and revealed that the states of $\mathrm{Cu}^{2+}$ in the surface of the composite particles was $\mathrm{Cu}-\mathrm{Si}-\mathrm{O}$ mineral phase and $\mathrm{CuO}\left(\mathrm{Cu}(\mathrm{OH})_{2}\right)$ polymerization precipitation. The bentonite-steel slag composite particles which can play a role of adsorption-coagulation synergism are excellent multifunctional green environmental mineral materials to treat acid mine drainage containing heavy metal ions.
\end{abstract}

Keywords: acid mine drainage containing $\mathrm{Cu}^{2+}$, bentonite, steel slag, composite particle adsorbent, ion exchange, surface complexation, adsorption, coagulation, synergistic reaction

\section{Introduction}

It is reported (Zuo and He 2013) that with the rapid development of industry, the world demand for mineral resources is increasing, while the problem of mine environmental pollution is becoming more and more serious due to the large amount of mining. The pollution of mine wastewater has become a global problem, in which acid mine drainage (AMD) is one of the most serious waste water. It is also reported (Cong and Zhao 2003) that acid mine drainage containing high concentrations of heavy metals and having low $\mathrm{pH}$ value, causing serious negative influence to the mining production and ecological environment. Acid mine drainage is one of the most serious environmental pollution to the mining industry. In recent years, it has been widely concerned by scholars at home and abroad.

At present, there are many methods to treat acid mine drainage, according to the different treatment mechanism, which can be divided into chemical, physical-chemical, microbiological and wetland methods. Neutralization precipitation is the most traditional and the most mature technology in chemical method. Adsorption is the most widely used technology in physical-chemical method. However, the neutralization precipitation method need to add neutralizing agent, flocculant and other chemical agents. The treatment cost is high, and the separation of solid and liquid is difficult. If good treatment effect is got, filtration or other technology is needed. The adsorption capacity of activated carbon which is often used as adsorbent for adsorption of heavy metal ions is low and the price is high. It can not neutralize the acid, and can not achieve the desired treatment effect. The effect of neutralization precipitation or adsorption treatment is poor. If the two are connected in series, the process flow is long and the processing cost is high.

In view of the above problems, the thesis used the characteristics of bentonite and steel slag, developing bentonite-steel slag composite particle adsorbent. It is reported (He et al 1999, Bellir et al 2013) that bentonite has good adsorption properties for heavy metal ions. It is also reported (Hu and Liu 2008, Zheng et al 1999, Lee et al 2012) that steel slag which is industrial alkaline waste material can not only release alkali and neutralize acid, but also precipitate heavy metal ions. The composite particles can not only release alkali and neutralize acid, but also play a role of adsorption-precipitation synergism to remove heavy metal ions. The composite particles with neutralization, adsorption, coagulation, filtration function can realize solidliquid separation, and can achieve solid waste resource utilization, thereby greatly reducing the treatment cost. In this paper, the mechanism of cation exchange, surface complexation, precipitation and coaglulation of composite particles on $\mathrm{Cu}^{2+}$ were verified. It revealed the adsorptioncoagulation mechanism of composite particles. It laid the theoretical foundation of exploring a high efficient cooperative treatment method of acid mine drainage containing heavy metal ions and developing a new type of multi-function environmental materials.

* Corresponding Author: L.P. Xiao, xxllpp11@126.com, phone: +86 13898563308

Copyright ( 2017 Canamaple Academia Services, http://press.camdemia.ca

DOI: $10.15273 /$ gree.2017.02.030 


\section{Materials and Methods}

\subsection{Materials}

Materials and reagents: (1) Bentonite (sodium bentonite) was taken from Wanpeng bentonite mine in Heishan county of Liaoning province. The particle size of bentonite was between $48 \sim 75 \mu \mathrm{m}$. (2) Steel slag was taken from a steel plant in Binzhou city, Shandong province. The particle size of steel slag was also between $48 \sim 75 \mu \mathrm{m}$. (3) $\mathrm{CuSO}_{4} \cdot 5 \mathrm{H}_{2} \mathrm{O}$, $\mathrm{Na}_{2} \mathrm{CO}_{3}, \quad \mathrm{Na}_{2} \mathrm{SO}_{4}, \quad \mathrm{NaOH}, \quad$ hydrochloric acid, phenolphthalein, methyl orange and all other chemicals were analytical grade.

The preparation of composite particles: a mixture was prepared with $50 \mathrm{~g}$ bentonite, $50 \mathrm{~g}$ steel slag and $5 \mathrm{~g}$ $\mathrm{Na}_{2} \mathrm{CO}_{3} .20 \mathrm{~mL}$ distilled water was added to the mixture. The mixture was uniformly stirred and granulated. The size of composite particles was $2 \mathrm{~mm}$. The aging time was $24 \mathrm{~h}$ in ventilated place. Finally, the particles was heated in muffle furnace (heated by $1 \mathrm{~h}$ in temperature $500{ }^{\circ} \mathrm{C}$ ).

Simulated acid mine drainage: the $\mathrm{CuSO}_{4} \cdot 5 \mathrm{H}_{2} \mathrm{O}$ was used in the preparation of acid mine drainage containing $\mathrm{Cu}^{2+}$. The mass concentration of $\mathrm{Cu}^{2+}$ was $80 \mathrm{mg} / \mathrm{L}$. The $\mathrm{pH}$ value was about 5 .

\subsection{Methods}

First, the adsorption experiment was carried out to test the removal efficiency of composite particles on $\mathrm{Cu}^{2+}$ from acid mine drainage. Then a contrast test was did using distilled water, to reveal the existence of cation exchange. It is reported (Mohapatra et al 2007) that the ionic strength is the important basis for judging the adsorption type. The ionic strength of simulated acid mine drainage was regulated to verify the surface complexation. Next, the experiment of alkali removal of bentonite-steel slag composite particles was carried out to measure the release of alkalinity at different time. According to the release rule of the alkalinity, the precipitation experiment was carried out to determine the effect of alkalinity which was released by composite particles on the precipitation of $\mathrm{Cu}^{2+}$. In addition, the dealkalization particles whose alkalinity had been completely released were used to determine the adsorption effect of composite particles. Finally, all results were compared to reveal the removal effect and mechanism of $\mathrm{Cu}^{2+}$ by bentonite-steel slag composite particles. XRD, FTIR and SEM analyses were used to further prove the mechanism. Specific experimental methods are as follows:

Adsorption experiment of $\mathrm{Cu}^{2+}$ on composite particles: $1.0 \mathrm{~g}$ composite particles and $200 \mathrm{~mL}$ simulated acid mine drainage were taken into a $500 \mathrm{~mL}$ conical flask. The conical flask was placed in thermostatic oscillator at 100 $\mathrm{r} / \mathrm{min}\left(25^{\circ} \mathrm{C}\right)$. All experiments were controlled under the above conditions. The removal amount of $\mathrm{Cu}^{2+}$ ions was measured.

Cation exchange experiment: a contrast test was done between simulated acid mine drainage and distilled water. The amounts of $\mathrm{Na}^{+}$released by composite particles in simulated acid mine drainage and distilled water were measured.
Surface complexation experiment: anhydrous $\mathrm{Na}_{2} \mathrm{SO}_{4}$ was used to regulate the simulated acid mine drainage, so that the $\mathrm{Na}^{+}$concentration was $0,0.1,1 \mathrm{~mol} / \mathrm{L}$. The removal amount of $\mathrm{Cu}^{2+}$ ions was measured.

Dealkalization experiment of composite particles: this experiment took nine conical flasks, each flask containing $1.0 \mathrm{~g}$ composite particles and $200 \mathrm{~mL}$ distilled water. All the conical flasks were placed in thermostatic oscillator to release alkalinity. The alkalinity of supernatant was measured at 5, 10, 30, 60, 120, 180, 240, 300, $360 \mathrm{~min}$. The alkalinity increment (convert to $\mathrm{NaOH}$ ) of the corresponding time was calculated. The dealkalization particles whose alkalinity had been completely released were placed in the oven to dry.

Precipitation experiment: according to the alkalinity increment of the corresponding time, the treatment of simulated acid mine drainage was performed by adding alkali alone $(\mathrm{NaOH})$. This experiment had no particles. At different times $(5,10,30,60,120,180,240,300,360 \mathrm{~min})$, the corresponding $\mathrm{NaOH}$ was added to the conical flask containing simulated acid mine drainage. The precipitation effect of $\mathrm{Cu}^{2+}$ was simulated.

Adsorption experiment of $\mathrm{Cu}^{2+}$ on dealkalization particles: this experiment was carried out with dealkalization particles. Other conditions were not changed.

Mechanism analysis: the composite particles were characterized by XRD (XRD-6100 Japan), SEM (FEI 200 Quanta) and FTIR (Nicolet is10 USA).

\section{Results and Discussion}

\subsection{Removal efficiency of composite particles on $\mathrm{Cu}^{2+}$}

The removal efficiency of composite particles on $\mathrm{Cu}^{2+}$ at different time is shown in Figure 1.

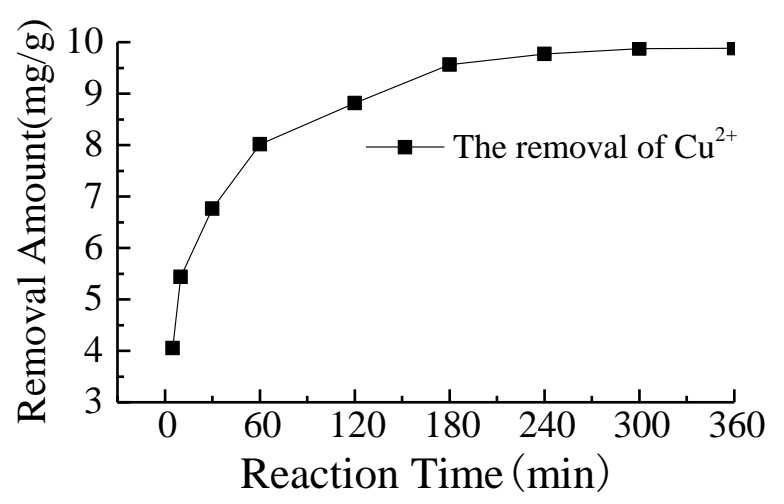

Figure 1. Removal efficiency of composite particles on $\mathrm{Cu}^{2+}$.

Figure 1 shows the effect of reaction time on the process. The removal rate of $\mathrm{Cu}^{2+}$ was fast at the initial stage of the reaction. With the passage of time, the removal rate decreased after $60 \mathrm{~min}$. The removal rate reached a state of equilibrium after $300 \mathrm{~min}$. When the experiment was carried out for 30 minutes, the surface of the composite particles was coated with a blue precipitate. The color of the solution gradually deepened with the reaction. Finally, the 
removal amount of composite particles on $\mathrm{Cu}^{2+}$ was 9.88 $\mathrm{mg} / \mathrm{g}$ when the reaction reached equilibrium. When the reaction was over, the $\mathrm{pH}$ value of the simulated acid mine drainage was between 7 8. The standard of simulated acid mine drainage can meet the national wastewater discharge standard. The composite particles played a role in neutralizing acid.

\subsection{Cation exchange of composite particles on $\mathrm{Cu}^{2+}$}

Figure 2(a) shows the amounts of $\mathrm{Na}^{+}$released by composite particles in simulated acid mine drainage and distilled water. At the same time, Figure 2(b) shows the average release rate of $\mathrm{Na}^{+}$in simulated acid mine drainage and distilled water at different time periods.

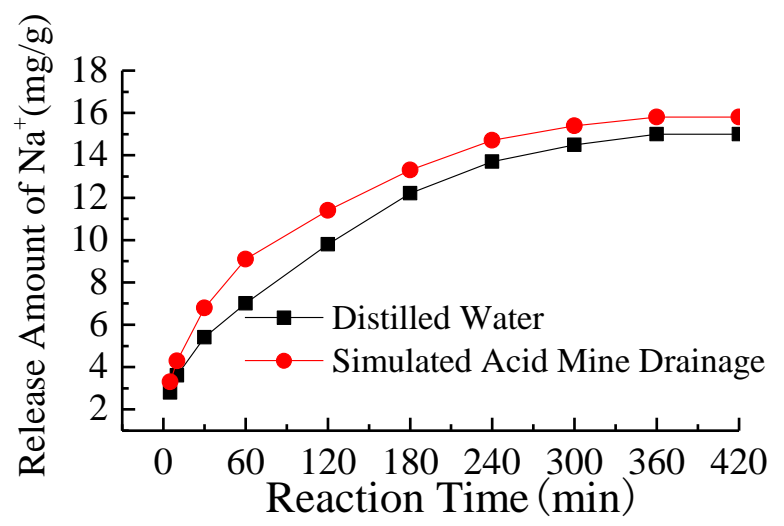

Figure 2. (a) The release amount contrast of $\mathrm{Na}^{+}$from composite particles in simulated acid mine drainage and distilled water.

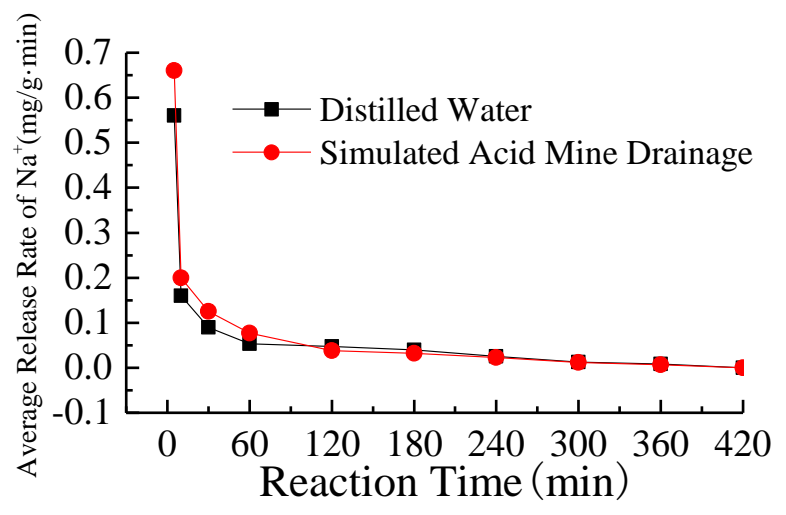

Figure 2. (b) The average release rate of $\mathrm{Na}^{+}$from composite particles in different phases.

Because sodium bentonite was used in the experiment, the $\mathrm{Na}^{+}$between the bentonite layer was used as the main cation exchange medium to exchange with $\mathrm{Cu}^{2+}$. It can be seen from Figure 2(a) that no matter in distilled water or in simulated acid mine drainage, the release of $\mathrm{Na}^{+}$increased with the reaction. However, the amount of $\mathrm{Na}^{+}$released by composite particles in simulated acid mine drainage was higher than that in distilled water. The results indicated that there was cation exchange in the treatment of $\mathrm{Cu}^{2+}$ with the composite particles. Due to the occurrence of cation exchange reaction in the reaction process, the $\mathrm{Na}^{+}$release rate in simulated acid mine drainage was faster than that in distilled water. As can be seen from Figure 2(b), the average release rate of $\mathrm{Na}^{+}$in simulated acid mine drainage was higher than that in distilled water at the first $60 \mathrm{~min}$. There must be cation exchange at this stage. Based on the experimental data in Figure 2 (a), it was found that the $\mathrm{Na}^{+}$ release increment caused by cation exchange was $2.1 \mathrm{mg} / \mathrm{g}$. The increment of $\mathrm{Na}^{+}$was equivalent to $2.92 \mathrm{mg} / \mathrm{g}$ of $\mathrm{Cu}^{2+}$. That was, the removal of $\mathrm{Cu}^{2+}$ due to cation exchange reaction was about $2.92 \mathrm{mg} / \mathrm{g}$.

\subsection{Surface complexation of composite particles on $\mathrm{Cu}^{2+}$}

Figure 3 shows the effect of ionic strength on the process.

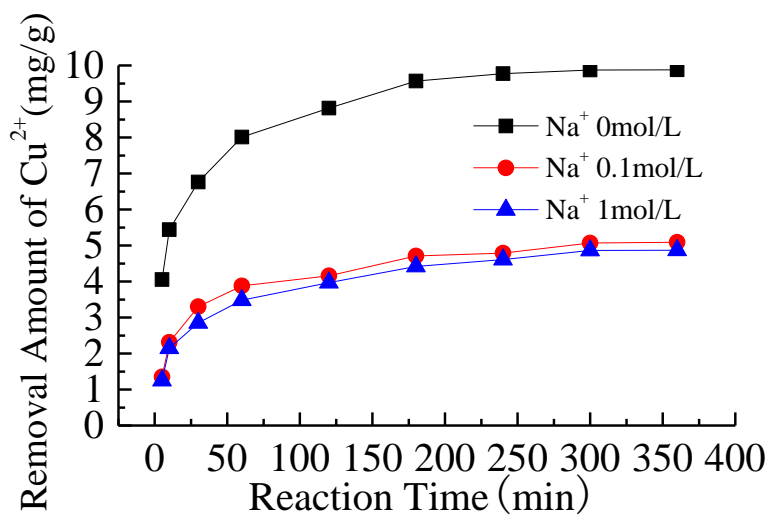

Figure 3. Ionic strength on the absorption of $\mathrm{Cu}^{2+}$ by composite particles.

As can be seen from Figure 3, the ionic strength had a great impact on the removal of $\mathrm{Cu}^{2+}$. However, compared with the $\mathrm{Na}^{+}$concentration was $0.1 \mathrm{~mol} / \mathrm{L}$, when the ionic strength increased by 10 times, the removal amount of $\mathrm{Cu}^{2+}$ changed little. If the ionic strength continued to be increased, the equilibrium removal amount was no longer changed. Namely, when $\mathrm{Na}^{+}$concentration was $1 \mathrm{~mol} / \mathrm{L}$, the ionic strength had reached the limit. It is reported (Tang et al 2001) that the removal amount of $\mathrm{Cu}^{2+}$ by composite particles will not be reduced, if the concentration of $\mathrm{Na}^{+}$ continues to be increased. Therefore, the $\mathrm{Na}^{+}$concentration was $1 \mathrm{~mol} / \mathrm{L}$ as the standard. When the adsorption reached equilibrium, the total removal amount of $\mathrm{Cu}^{2+}$ was 4.87 $\mathrm{mg} / \mathrm{g}$ in simulated acid mine drainage. Compared with 9.88 $\mathrm{mg} / \mathrm{g}$ under the condition of no ionic strength, the removal rate decreased by $5.01 \mathrm{mg} / \mathrm{g}$. It is reported (Cao et al 2014) that the ionic strength has a significant effect on the ion exchange and surface complexation. Thus, the $5.01 \mathrm{mg} / \mathrm{g}$ can be considered as the total amount of ion exchange and surface complexation. After deducting the ion exchange amount of $2.92 \mathrm{mg} / \mathrm{g}$, the remaining $2.09 \mathrm{mg} / \mathrm{g}$ is the amount of surface complexation. 


\subsection{Adsorption-coagulation synergism of composite particles on $\mathrm{Cu}^{2+}$}

Figure 4 shows the removal efficiency of $\mathrm{Cu}^{2+}$ by composite particles, dealkalization particles and single addition alkali at different time.

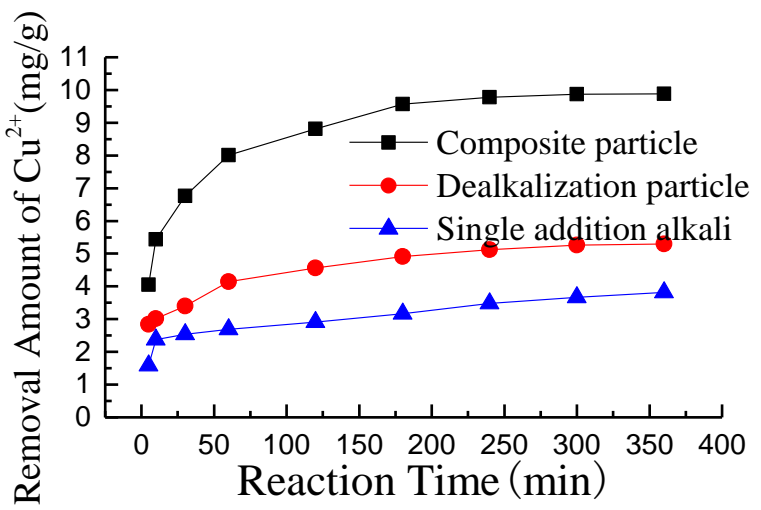

Figure 4. The removal efficiency of $\mathrm{Cu}^{2+}$ by composite particles, dealkalization particles and single addition alkali.

In Figure 4, the removal amount of $\mathrm{Cu}^{2+}$ by dealkalization particles was lower than that by composite particles. When the alkalinity was removed of composite particles, the precipitation effect of $\mathrm{Cu}^{2+}$ was little or even disappeared. In the process of reaction, the solution of simulated acid mine drainage was clear, and the surface of the dealkalization particles were not coated with any precipitate. Therefore, in the process of reaction, the removal of $\mathrm{Cu}^{2+}$ by dealkalization particles only had the effects of ion exchange, electrostatic interaction and complexation reaction. The final removal amount of $\mathrm{Cu}^{2+}$ by dealkalization particles can be seen as the removal of $\mathrm{Cu}^{2+}$ by the adsorption of composite particles, which is $5.3 \mathrm{mg} / \mathrm{g}$.

After reacting 360 minutes, the removal amount of $\mathrm{Cu}^{2+}$ by single addition alkali was only $3.8 \mathrm{mg} / \mathrm{g}$, which could be considered as the removal of precipitation. The total removal amount of $\mathrm{Cu}^{2+}$ by dealkalization particles and single addition alkali was $9.1 \mathrm{mg} / \mathrm{g}$, which was less than the removal amount of $\mathrm{Cu}^{2+}$ by composite particles. The results showed that the removal of $\mathrm{Cu}^{2+}$ by composite particles not only included adsorption and chemical precipitation, but also had the synergistic effect of adsorption and precipitation. Namely, there was adsorption-coagulation synergism.

\section{Mechanism}

\subsection{Layer spacing analysis of composite particles}

Figure 5 shows the layer spacing of the composite particles before and after the adsorption experiment.

It is reported ( $\mathrm{Li}$ et al 1986) that the adsorption of heavy metals would increase the spacing of montmorillonite layers. The composite particles were composed of montmorillonite and steel slag, which retained the properties of montmorillonite.

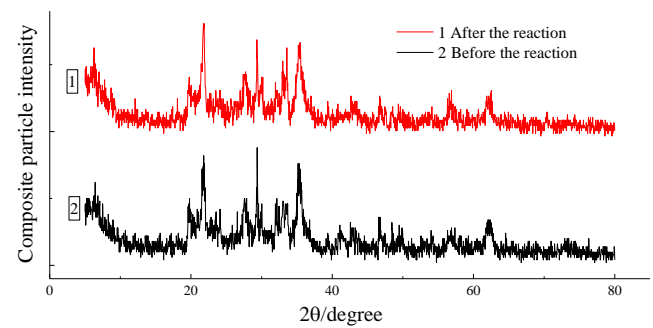

Figure 5. The layer spacing changes of composite particles.

Before the adsorption experiment, the composite particle layer spacing was $15.5285 \AA$. After the adsorption experiment, the composite particle layer spacing increased to $15.7623 \AA$. The result showed that the hydrated copper ions entered into the inter layer of the composite particles. It proved the existence of ion exchange.

\subsection{FTIR analysis of composite particles}

Figure 6 shows the FTIR spectra of the composite particles before and after the adsorption experiment.

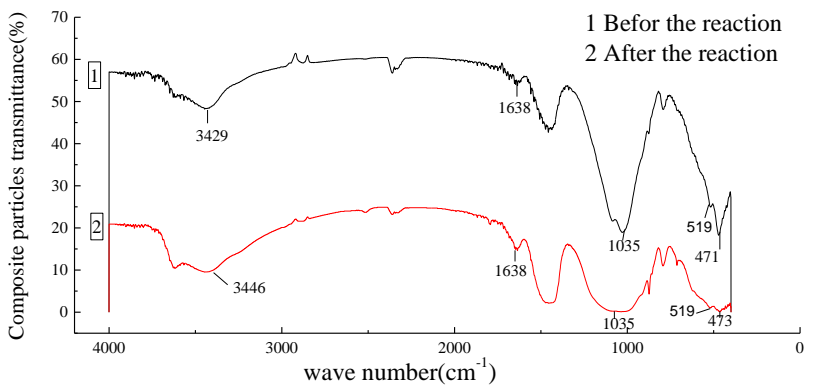

Figure 6. The FTIR spectra of composite particles before and after the adsorption experiment.

It can be seen from Figure 6 that the stretching and bending vibration peaks of the adsorbed water $\mathrm{H}-\mathrm{O}-\mathrm{H}$ in the composite particles which had adsorbed $\mathrm{Cu}^{2+}$ moved to the high frequency direction. It indicated that the hydrated copper ions had entered into the composite particle layer, leading to the increase of water content in the composite particles. There was a strong peak near $1035 \mathrm{~cm}^{-1}$, which was the stretching vibration absorption peak of $\mathrm{Si}-\mathrm{O}$ bond. The absorption peak near $519 \mathrm{~cm}^{-1}$ was the bending vibration absorption peak of $\mathrm{Si}-\mathrm{O}$ bond, and the absorption peak at $471 \mathrm{~cm}^{-1}$ corresponded to the peak of $\mathrm{Si}-\mathrm{O}-\mathrm{Al}$ bending vibration absorption. The FTIR spectra showed that $\mathrm{Si}-\mathrm{O}$ and $\mathrm{Si}-\mathrm{O}-\mathrm{Al}$ adsorption peak did not change the wave number after the composite particles adsorbing $\mathrm{Cu}^{2+}$, but the peak had widened. The results showed that $\mathrm{Cu}^{2+}$ dad reacted with silicate and aluminosilicate. It was proved that there existed the surface complexation.

\subsection{SEM analysis of composite particles}

Figure 7 shows the SEM micrographs of the composite particles at different time of the adsorption experiment. 


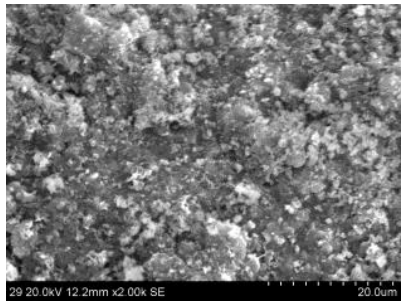

$5 \min$

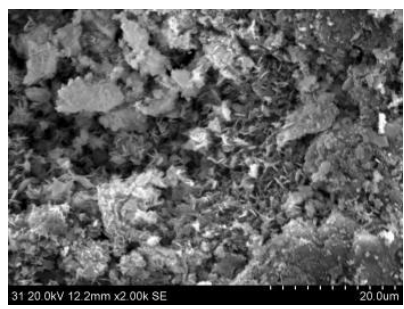

$180 \mathrm{~min}$

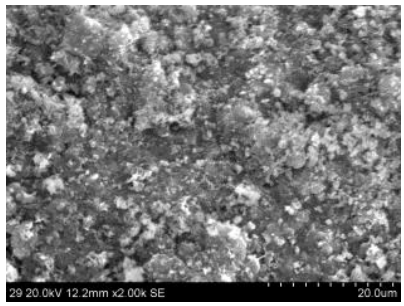

$10 \min$

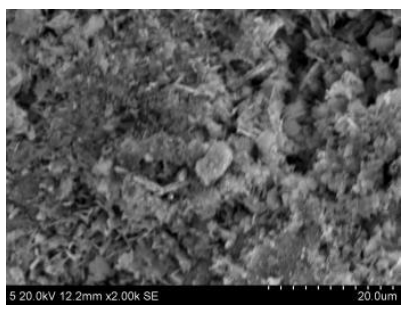

$360 \mathrm{~min}$
Figure 7. The SEM surface microstructure of composite particles absorbing $\mathrm{Cu}^{2+}$ at different time.

As can be seen from Figure 7, the adsorbed $\mathrm{Cu}^{2+}$ first occupied the surface and pore of the composite particles, and produced a small amount of small elliptical needle precipitation. At the initial stage of the reaction, a single individual was attached to the surface of the composite particles. With the passage of time, the precipitate was clustered and attached to the surface of the composite particles. Subsequently, the surface precipitation of the composite particles continuously adsorbed $\mathrm{Cu}^{2+}$ and sediment. The $\mathrm{Cu}^{2+}$ and sediment were clustered and adsorbed on the surface of the composite particles. The polymerization precipitation occurred.

The composite particles were composed of silicate (see Figure 8(a)). It is reported (Liu and $\mathrm{Wu} 2006$ ) that the silicate hydroxyl groups on the surface of the particles could occur ionic reaction. The ionic reaction would lead to the generation of negative charges on the surface of the particles. The ionic reaction was that: $\mathrm{SiOH}=\mathrm{SiO}^{-}+\mathrm{H}^{+}$. It was easy to adsorb positively charged ions on the surface of particles. At the same time, the surface of the composite particles was hydrolyzed to release alkali and neutralize acid, and $\mathrm{Cu}^{2+}$ was adsorbed to form $\mathrm{Cu}(\mathrm{OH})_{2}$. According to Fajans rule which was reported (Shen et al 2012), the $\mathrm{Cu}^{2+}$ in the solution was most easily adsorbed on the surface of $\mathrm{Cu}(\mathrm{OH})_{2}$ particles which were adsorbed on the surface of the composite particles, so as to realize the further agglomeration of $\mathrm{Cu}^{2+}$. Therefore, combined with the removal effect of $\mathrm{Cu}^{2+}$ and the microscopic characterization of composite particles, the results revealed that the mechanism of composite particles on $\mathrm{Cu}^{2+}$ not only included adsorption and surface chemical precipitation, but also included coaglulation. There was adsorption-coagulation synergism.

\subsection{XRD phase analysis of composite particles}

Figure 8 shows the mineral phases of the composite particles before and after the adsorption experiment.

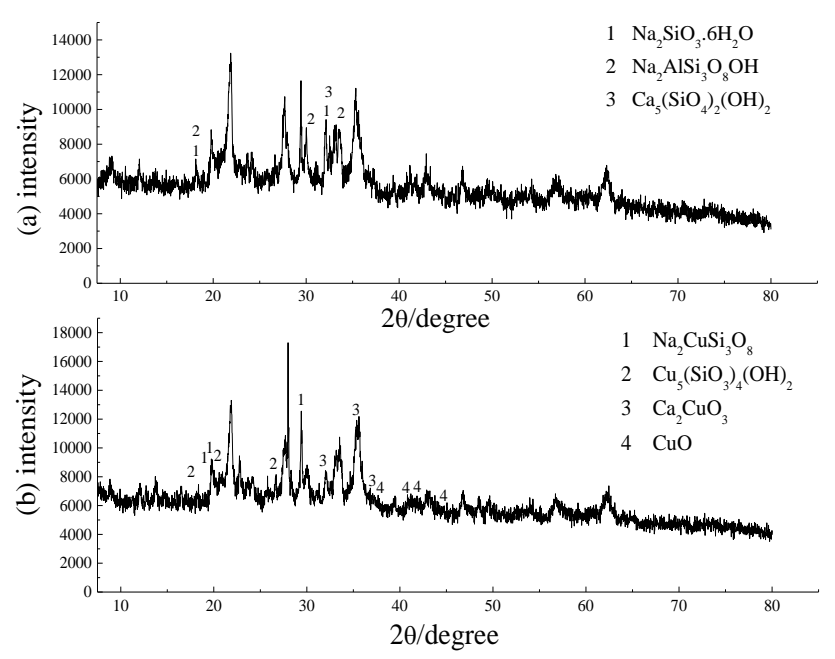

Figure 8 . The XRD patterns of composite particles before (a) and after (b) the adsorption experiment.

As can be seen from Figure 8, the mineral phases of composite particles before the adsorption experiment were weakened or even disappeared in the reaction process, such as $\mathrm{Na}_{2} \mathrm{SiO}_{3} \cdot 6 \mathrm{H}_{2} \mathrm{O}, \mathrm{Na}_{2} \mathrm{AlSi}_{3} \mathrm{O}_{8} \mathrm{OH}, \mathrm{Ca}_{5}\left(\mathrm{SiO}_{4}\right)_{2}(\mathrm{OH})_{2}$. The XRD pattern of the composite particles after the adsorption experiment showed that a large number of new mineral phases were produced, such as $\mathrm{Na}_{2} \mathrm{CuSi}_{3} \mathrm{O}_{8}$, $\mathrm{Cu}_{5}\left(\mathrm{SiO}_{3}\right)_{4}(\mathrm{OH})_{2}, \mathrm{Ca}_{2} \mathrm{CuO}_{3}$. The results indicated that there were surface complexation and coaglulation. The $\mathrm{CuO}$ on the composite particles was produced by $\mathrm{Cu}(\mathrm{OH})_{2}$ after high temperature drying. It was indicated that chemical precipitation occurred during the reaction.

XRD patterns and FTIR spectra showed that the composite particles contained a large number of $\mathrm{SiO}_{4}{ }^{4-}$ groups. In the solid-liquid system, the surface of the composite particles can be formed with water to hydrous oxide coating. The surface of the composite particles was negatively charged. This was favorable for adsorption and complexation. The complexation between the silicate hydroxyl group and $\mathrm{Cu}^{2+}$ on the surface of the composite particles can be expressed as follows:

Firstly, the silicate hydroxyl group occurred ionic reaction: $\mathrm{SiOH}=\mathrm{SiO}^{-}+\mathrm{H}^{+}$. Secondly, $\mathrm{Cu}^{2+}$ reacted with water molecules to form hydrated ions: $\mathrm{Cu}^{2+}+\mathrm{H}_{2} \mathrm{O}=$ $\mathrm{CuOH}^{+}+\mathrm{H}^{+}$. Finally, the complexation between silicate and hydrated ions was that: $\mathrm{SiO}^{-}+\mathrm{Cu}^{2+}=\mathrm{SiOCu}^{+}$or $\mathrm{SiO}^{-}+$ $\mathrm{CuOH}^{+}=\mathrm{SiOCuOH}$.

Therefore, the states of $\mathrm{Cu}^{2+}$ in the surface of the composite particles were $\mathrm{Cu}-\mathrm{Si}-\mathrm{O}$ mineral phase and $\mathrm{CuO}\left(\mathrm{Cu}(\mathrm{OH})_{2}\right)$ polymerization precipitation.

\section{Conclusions}

(1) When the composite particles were used to treat acid mine drainage containing $\mathrm{Cu}^{2+}$, they could release alkali to 
neutralize acid. The adsorption and chemical precipitation of $\mathrm{Cu}^{2+}$ occurred in the whole reaction process. The removal amount of $\mathrm{Cu}^{2+}$ was $9.88 \mathrm{mg} / \mathrm{g}$ when the reaction reached equilibrium;

(2) From the experimental data, it can be seen that the cation exchange reaction mainly occurred in the early stage of the reaction. The FTIR spectra revealed the existence of surface complexation; The XRD patterns revealed the existence of cation exchange and also revealed that the states of $\mathrm{Cu}^{2+}$ in the surface of the composite particles was $\mathrm{Cu}-\mathrm{Si}-\mathrm{O}$ mineral phase and $\mathrm{CuO}\left(\mathrm{Cu}(\mathrm{OH})_{2}\right)$ polymerization precipitation;

(3) According to the experimental phenomena and the SEM surface microstructure of composite particles at different time, it can be seen that the removal mechanism of $\mathrm{Cu}^{2+}$ by composite particles included not only adsorption but also surface chemical precipitation. It also revealed that the composite particles would continue to adsorb and coagulate $\mathrm{Cu}^{2+}$ after the composite particles surface adsorbing $\mathrm{Cu}^{2+}$ and forming precipitate. Namely, there was adsorption-coagulation synergism;

(4) The bentonite-steel slag composite particles which could play a role of adsorption-precipitation synergism, overcame the limitations of single material, single method and single function. The research provided a theoretical basis for the development and application of a new type of multifunctional mineral environmental material, which could remove heavy metal ions and reduce acidity.

\section{Acknowledgement}

This research project is made possible through the financial support from National Natural Science Foundation (51474122, 51174267) and Liaoning province "Baiqianwan Talents Project" (2014921069). The authors extend special thanks to the above projects.

\section{References}

Bellir, K., M.B. Lehocine and A.H. Meniai, 2013. Zinc removal from aqueous solutions by adsorption onto bentonite. Desalination and Water Treatment, 51(2527): 5035 - 5048.

Cao, X.Q, Y. Zhang, J. Qiu, X.J. Lu, L.H. Wang, Y.N. Chen and Y.H. Wang, 2014. Adsorption and mechanism of nickel ions form aqueous solution by bentonite. Journal of the Chinese ceramic society, 42(11): $1448-1454$. DOI:10.7521/j.issn.0454-5648.2014.11.16

Cong, Z.Y. and F.H. Zhao, 2003. Current situation and prospect of the research on acid mine drainage. China Mining Magazine, 12(3): 15 - 18.

He, H.P., J.G. Guo, X.D. Xie, et al, 1999. Experimental studies on the selective adsorption of heavy metal ions by montmorillonite and so on. Acta Mineralogica Sinica, 19(2): $231-235$.

Hu, Y.F. and F.Z. Liu, 2008. The research of steel slag in waste water processing. Journal of Shandong Polytechnic University, 22(3): 38 - 41.

Lee, C.G., J.A. Park and S.B. Kim, 2012. Phosphate removal from aqueous solutions using slag microspheres. Desalination and Water Treatment, 44(1/2/3): 229-236.

Li, P.Y., W.S. Yuan, H.F. Lin and D.C. Jiang, 1986. Discussion on factors influencing interlayer spacing variation of montmorillonite. Nanjing Institute of Geology and Mineral Resources, Chinese Academy of Geological Sciences, 7(1): 61 - 76.

Liu, Y. and P.X. Wu, 2006. Summary ary of research on the interface reaction between heavy metals and clay. Techniques and Equipment for Environmental Pollution Control, 7(1): 17 - 21.

Mohapatra, D., D. Mishra, G.R. Chaudhury and R.P. Das, 2007. Arsenic adsorption mechanism on clay minerals and its dependence on temperature. Korean Journal of Chemical Engineering, 24(3): 426 - 430. DOI:10.1007/s11814-007-0073-2.

Shen, Z., Z.G. Zhao and W.L. Kang, 2012. Colloid and surface chemistry, 4th Ed. Chemical Industry Press, Beijing.

Tang, Y.Q., H. Niu and J. Lin, 2001. Mechanism of lead(II) biosorption by waste mycelium of penicillium chrysogenum. Journal of Sichuan University (Engineering Science Edition), 33(4): 45 - 49.

Zheng, L.S., S.L. Wang and H. Liu, 1999. Treat wastewater which contains chromium with slag. Materials Protection, 32(5): 40 - 41.

Zuo, L. and Q.F. He, 2013.The state-of-art and progress of the treatment technology for acid mine waste water. Environment Engineering, 31(5): 35 - 38. 